\title{
Method for NIR Reflectance Estimation with Visible Camera Data based on Regression for NDVI Estimation and its Application for Insect Damage Detection of Rice Paddy Fields
}

\author{
Kohei Arai ${ }^{1}$ \\ Graduate School of Science and Engineering \\ Saga University \\ Saga City, Japan \\ Kenji Gondoh ${ }^{2}$ \\ Saga Prefectural Agricultural Research Institute \\ Saga Prefectural Government, \\ Saga City, Japan
}

\author{
Osamu Shigetomi ${ }^{2}$ \\ Saga Prefectural Agricultural Research Institute \\ Saga Prefectural Government, \\ Saga City, Japan \\ Yuko Miura $^{2}$ \\ Saga Prefectural Agricultural Research Institute \\ Saga Prefectural Government, \\ Saga City, Japan
}

\begin{abstract}
Method for Near Infrared: NIR reflectance estimation with visible camera data based on regression for Normalized Vegetation Index: NDVI estimation is proposed together with its application for insect damage detection of rice paddy fields. Through experiments at rice paddy fields which is situated at Saga Prefectural Agriculture Research Institute SPARI in Saga city, Kyushu, Japan, it is found that there is high correlation between NIR reflectance and Green color reflectance. Therefore, it is possible to estimate NIR reflectance with visible camera data which results in possibility of estimation of NDVI with drone mounted visible camera data. As is well known that the protein content in rice crops is highly correlated with NIR intensity, or reflectance of rice leaves, it is possible to estimate rice crop quality with drone based visible camera data.
\end{abstract}

Keywords-Rice crop; Rice leaf; Nitrogen content; Protein content; NIR reflectance; Water content; Size of rice leaves; Weight of rice crops

\section{INTRODUCTION}

Vitality monitoring of vegetation is attempted with photographic cameras [1]. Grow rate monitoring is also attempted with spectral reflectance measurements [2]. BiDirectional Reflectance Distribution Function: BRDF is related to the grow rate for tealeaves [3]. Using such relation, sensor network system with visible and near infrared cameras is proposed [4]. It is applicable to estimate nitrogen content and fiber content in the tealeaves in concern [5]. Therefore, damage grade can be estimated with the proposed system for rice paddy fields [6]. This method is validated with Monte Carlo simulation [7]. Also Fractal model is applied to representation of shapes of tealeaves [8]. Thus the tealeaves can be asse3ssed with parameters of the fractal model. Vitality of tea trees are assessed with visible and near infrared camera data [9]. Rice paddy field monitoring with radio-control drone mounting visible and Near Infrared: NIR camera is proposed [10] while the method for rice quality evaluation through nitrogen content in rice leaves is also proposed [11].

The fact that protein content in rice crops is highly correlated with NDVI which is acquired with visible and Near Infrared: NIR camera mounted on drone is well reported [10]. It also is reported that nitrogen content in rice leaves is correlated to NDVI as well. Protein content in rice crop is negatively proportional to rice taste. Therefore, rice crop quality can be evaluated through NDVI observation of rice paddy field. Relation among nitrogen content in rice leaves, amount of fertilizer, NDVI and protein content in rice crops has to be clarified [11]. There are some indexes which show quality of rice crops, protein content, nitrogen content, etc. in the rice leaves. Meanwhile, there are some indexes for harvest amount, the number of ear in the stump, ear length, crop weight, etc. It should be depending on circumstances of geometric condition, soil condition, meteorological condition, water supply condition, fertilizer amount and rice stump density. Intensive study paddy fields have a variety of conditions. Drone mounted NIR camera has a good enough spatial resolution. Therefore, rice crop quality and harvest amount is evaluated as a function of water supply condition and fertilizer amount and rice stump density. These evaluation methods are well reported in the previous papers [12]. Another great concern is insect damages. Rice paddy fields situated in Asia are used to be damaged by insects, such as disappearing. In particular, brown colored disappearing are comes first depending on meteorological conditions followed by back black disappearing for the rice paddy fields in Japan. They are migrating from South-East Asian countries. They propagate so rapidly. Therefore, insect damages have to be detected so quickly and urgently. One of the effective methods for detection of insect damage is to monitor rice paddy field with drone mounted cameras. Un fortunately, most of cameras which can be mounted on drones are visible cameras. On the other hand, Normalized Difference Vegetation Index: NDVI is 
quite useful for monitoring vigor, rice crop quality and harvest amount. It, however, can be calculated with Near Infrared: NIR data. Meanwhile, vigor, rice crop quality, and harvest amount are closely related to not only NIR reflectance but also green color reflectance, the sensitivity for the green color reflectance is poorer than that of NIR reflectance remarkably though. The proposed method is intended for estimation of NIR reflectance with visible camera data for estimation of NDVI which results in estimation of vigor, rice crop quality, and harvest amount.

The proposed method is described in the next section followed by experiments. The experimental results are validated in the following section followed by conclusion with some discussions.

\section{PROPOSED METHOD}

The proposed method is based on linear regression. NIR camera data is compared to the visible camera data. The correlation coefficient between NIR intensity and Red, Green, Blue: RGB of visible intensity, and determination coefficients are estimated together with regressive equation.

\section{EXPERIMENTS}

\section{A. Rice Crop Field at Saga Prefectural Agriculture Research} Institute: SPARI

Fig.1 (a) shows the Location (A) and (B) Layout of the test site of rice crop field at SPARI which is situated at $33^{\circ} 13^{\prime} 11.5^{\prime \prime}$ North, $130^{\circ} 18^{\prime} 39.6^{\prime \prime E a s t, ~ a n d ~ t h e ~ e l e v a t i o n ~ o f ~} 52$ feet on the Google map. B and A in the Fig.1 (b) shows layout map for intensive study rice paddy fields.

Three are some experimental fields in the SPARI. Black rectangle in Fig.1 (b) indicates intensive study paddy field.

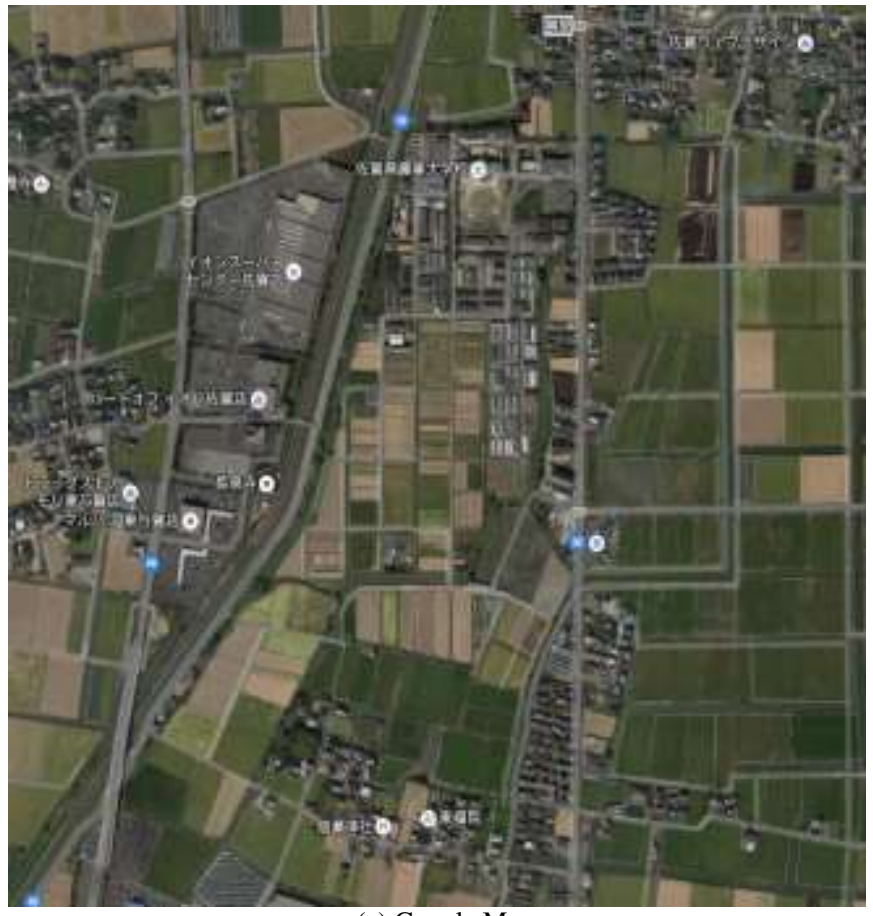

(a) Google Map

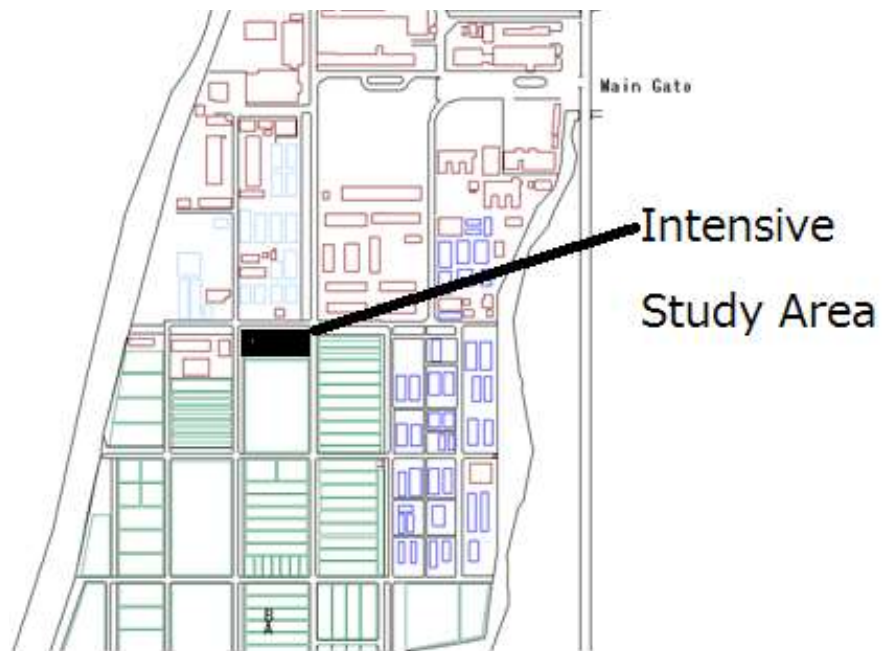

(b) Layout of the paddy fields

Fig. 1. Location of Saga Prefectural Agriculture Research Institute: SPARI on Google map

"Sagabiyori" of rice specie and some others are planted in the intensive study area. In particular, no parricide is used in this field. Therefore, the field is damaged by insect when some insects come flying over the field easily.

\section{B. Acquired Data}

Drone mounted visible camera data are acquired at 9:00 on August 23, 13:00 on September 5, 9:00 on September 14, 14:00 on September 15, and 10:00 on September 16, while ground truth data and NIR reflectance are measured at 9:0010:00 on August 23, and 10:00 on September 17, respectively. Fig. 2 shows the acquired drone mounted camera images.

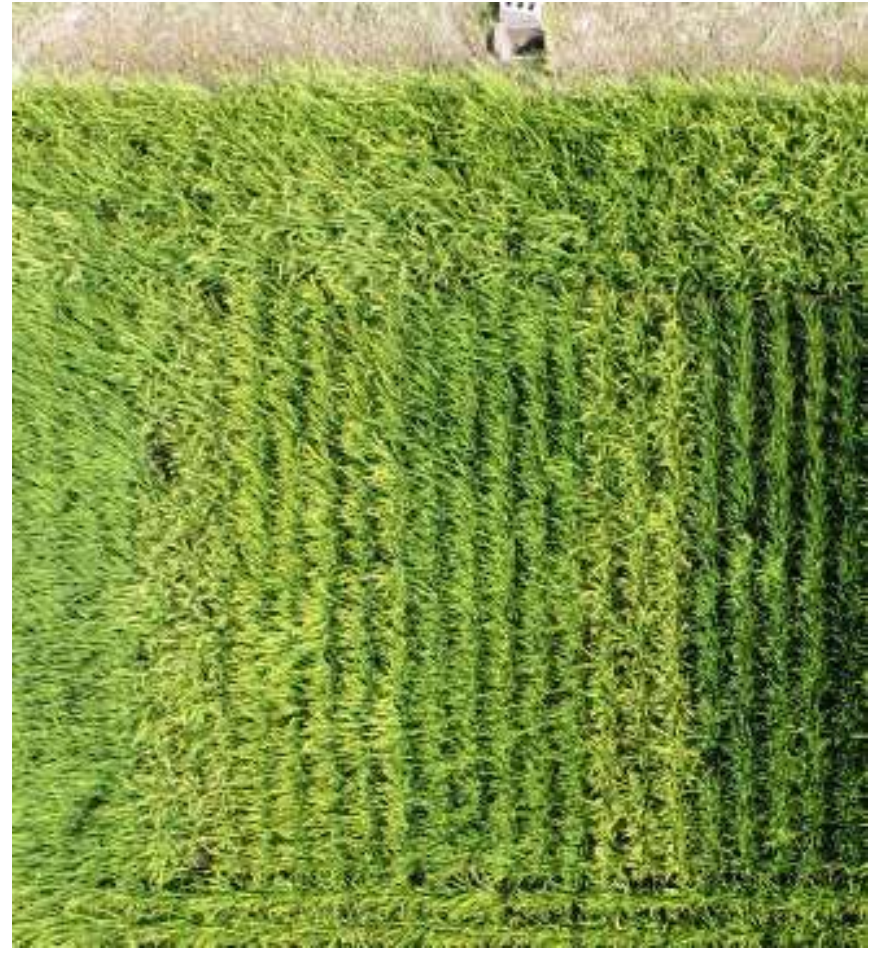

(a) 9:00 on August 23 


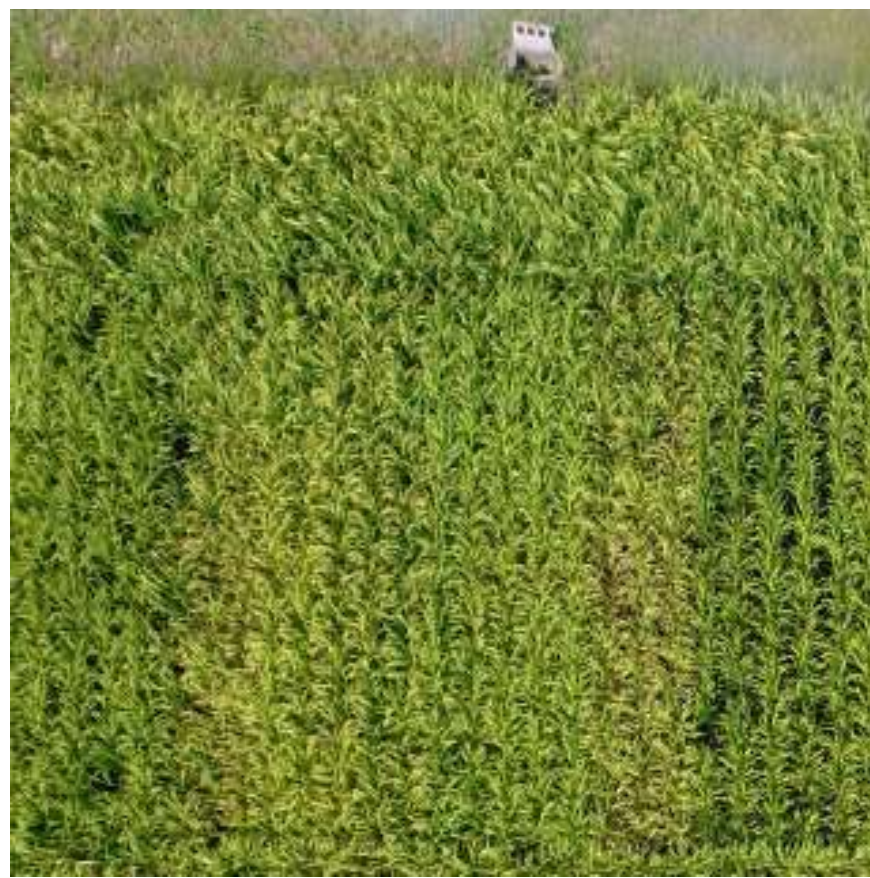

(b) 13:00 on September 5

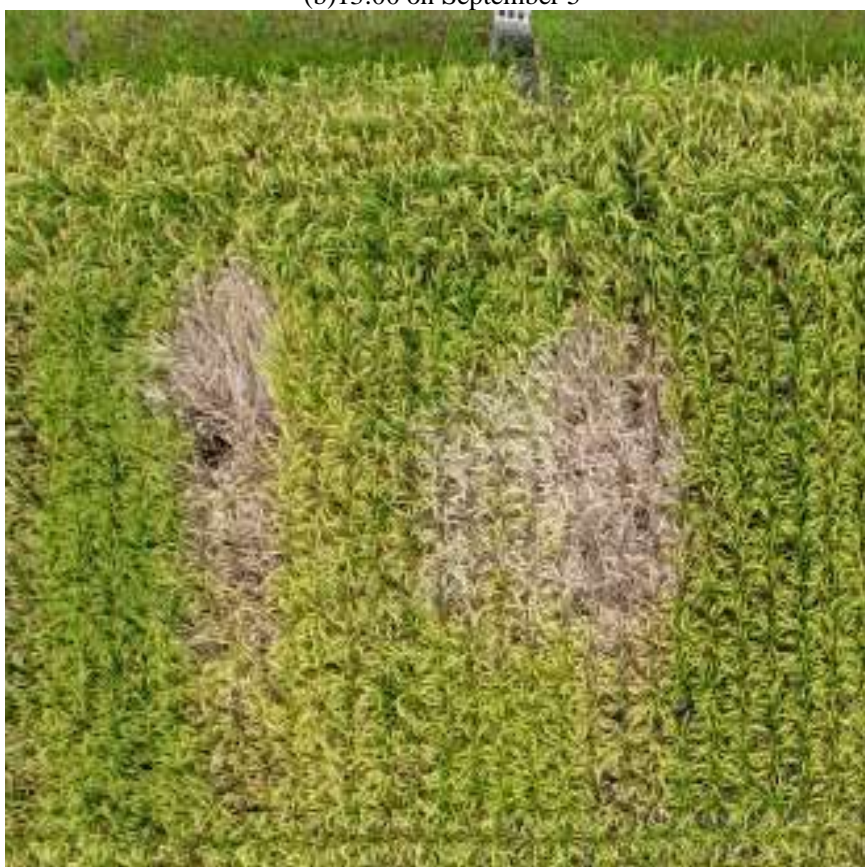

(c) 9:00 on September 14

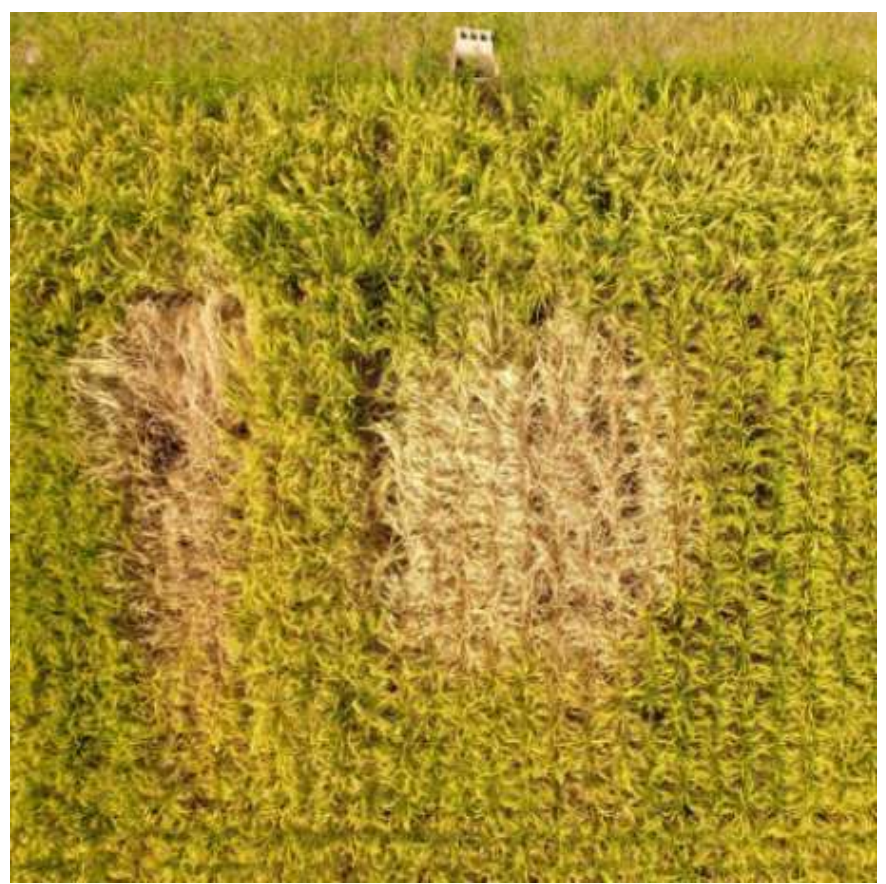

(d) 14:00 on September 15

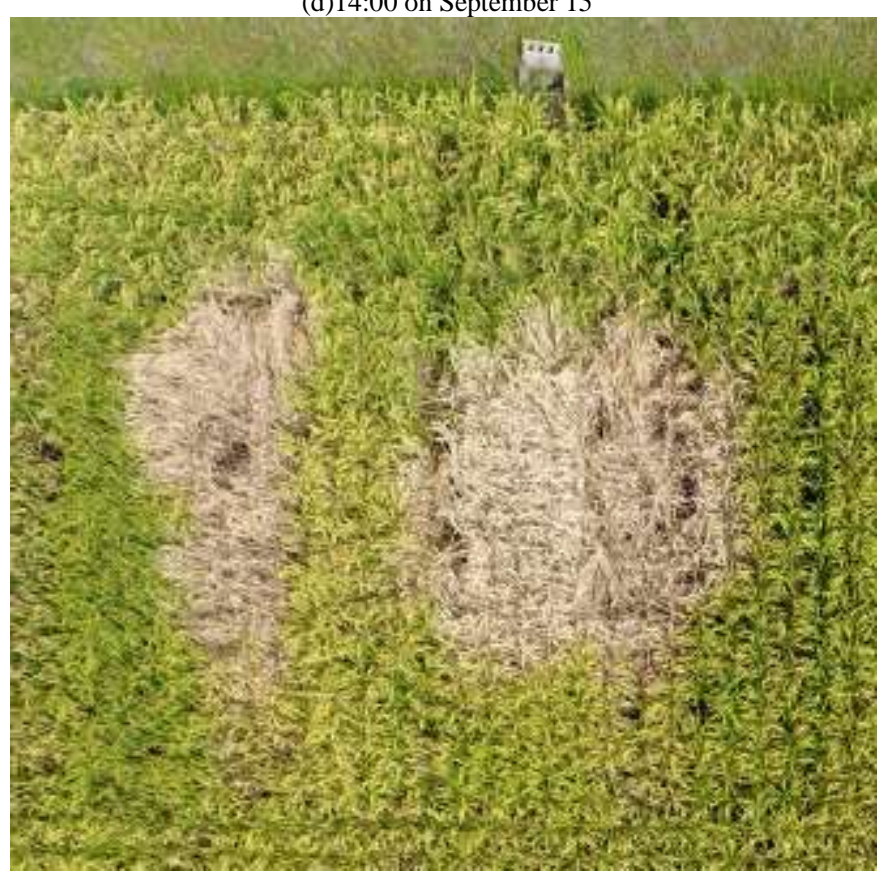

(e)10:00 on September 16

Fig. 2. Acquired drone mounted visible camera data 
Weather conditions are as follows,

August 23

$1005.2 \mathrm{hPa}$

30.8 Deg.C

$61.7 \%$

$2.5 \mathrm{~m} / \mathrm{s}$

33:12'59.2”N, 130:18'45.6”'

GM:31.8-40.7

September 17

33:13'18.6”'N, 130:18'40.6”'E

30.7 Deg.C

$66.4 \%$

$1011.6 \mathrm{hPa}$

$\mathrm{GM}=7.7-22.6$

GM denotes Green Meter value. Due to the fact that the GM value measured on September 17 is poorer than that on August 23, it is found that rice paddy field has severe damage due to insects.

These are a portion of drone mounted visible camera images at almost same area. Whole image color varies depending on the sun illumination angles. Also, two major damaged areas are getting expanded. In particular, large change can be seen during from September 5 and September 14. Meanwhile, ground based visible camera data and NIR camera data are acquired at 9:00-10:00 on August 23 and at 10:00 on September 17, respectively. Fig. 3 shows the acquired visible and NIR camera imagery data. The field can be divided into two areas, damaged area and normal area clearly.

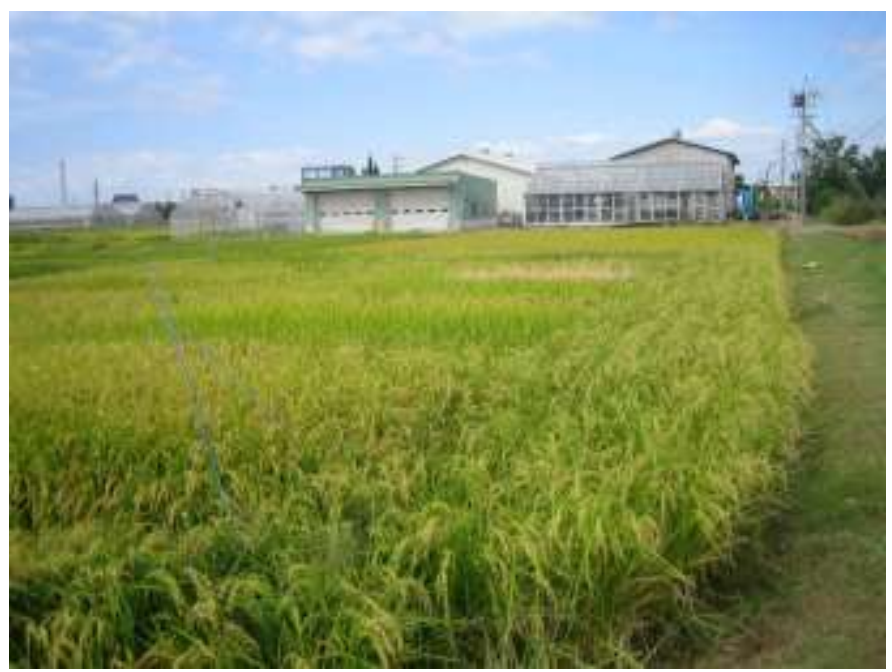

(a) Visible image from far

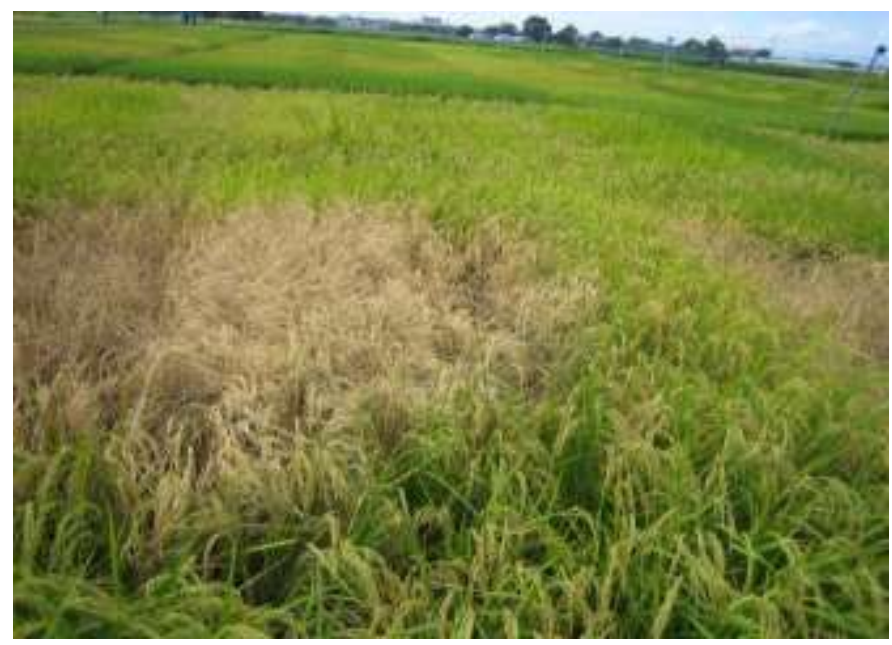

(b) Close-up visible image

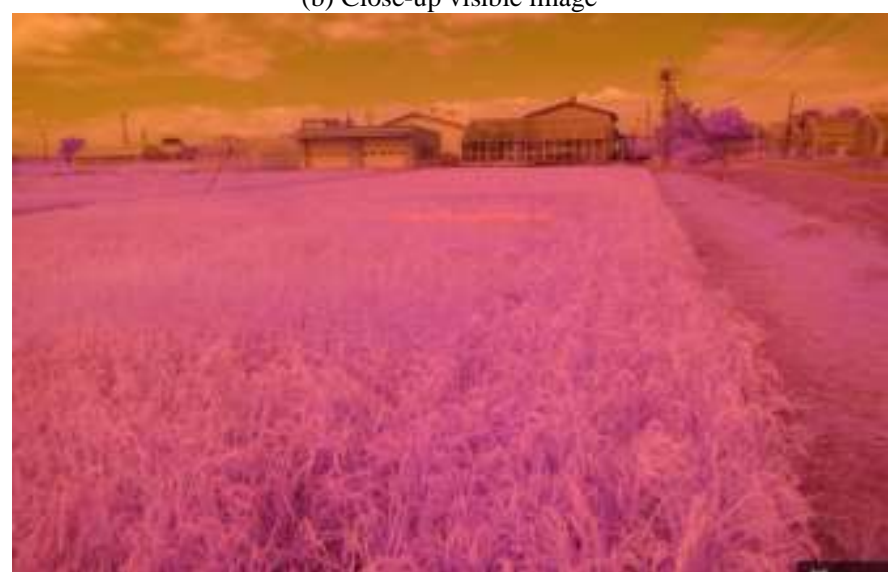

(c) NIR image from far

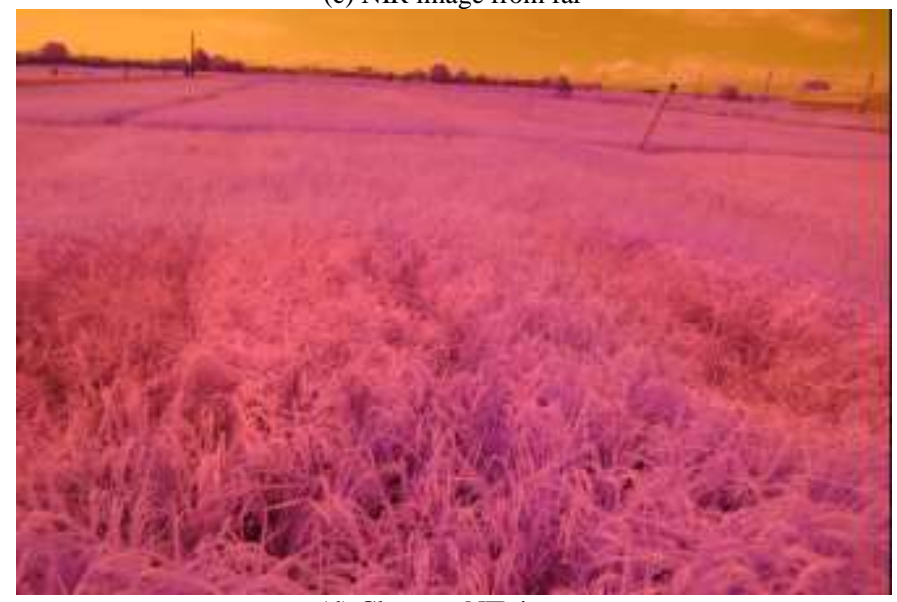

(d) Close-up NIR image

Fig. 3. Acquired visible and NIR camera imagery data. 
Spectral reflectance is measured at the intensive study paddy fields on August 23 and September 17 2016. In the intensive study area can be divided into two portions, (1) damaged and (2) normal fields. (1) field is damaged due to insects while (2) field is not. These are under totally equal condition the species of rice crops are different from each other. These are named as "damage" and "normal" fields. The spectral reflectance measured on August 23 is shown in Fig.4 (a) while that on September 17 is shown in Fig.4 (b), respectively.

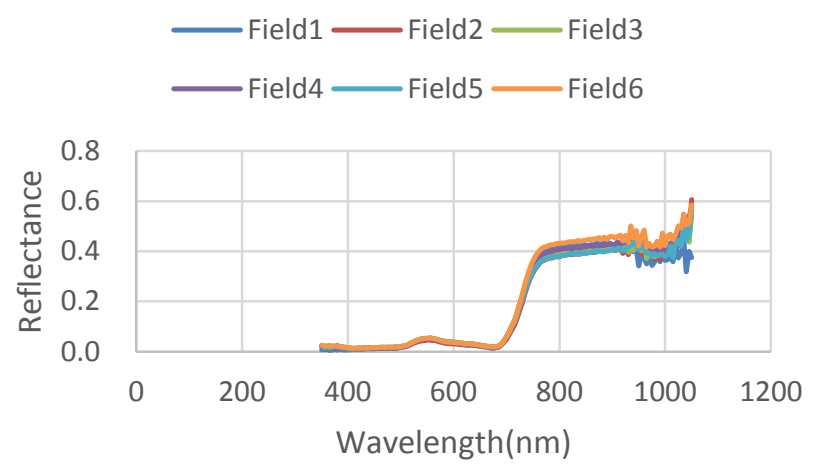

(a) August 23

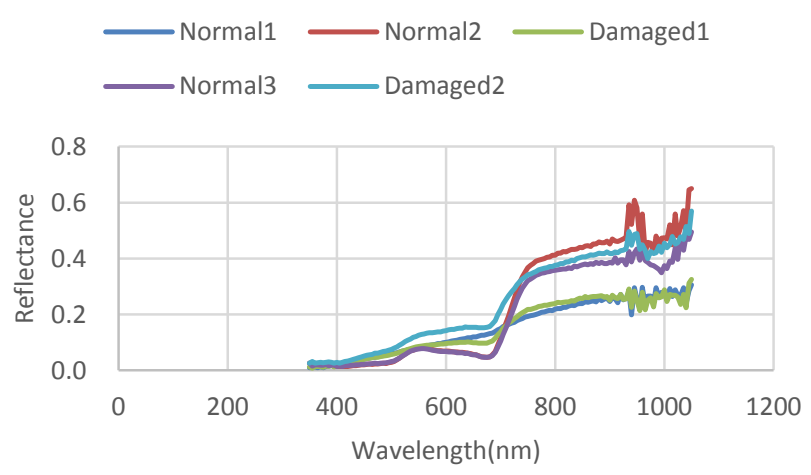

(b) September 17

Fig. 4. Spectral reflectance measured at the intensive study paddy field in SPARI in 2016

It is clear that damaged paddy fields show remarkable low reflectance at the near infrared wavelength region while that for normal paddy fields show stable NIR reflectance in comparison to that of August 23.

\section{Regressive Analysis}

From the drone based visible camera data, insect damage trend can be analyzed. NIR and RGB intensities are plotted as a function of time being as shown in Fig.5. The detailed color and NIR intensity is shown in Table 1 as well. In these figure and table, suffix d denotes "damaged area" while $\mathrm{n}$ denotes "normal area", respectively.

The color of the damaged area is changed to white. Therefore, intensity is increased after the rice paddy field is damaged due to insects.

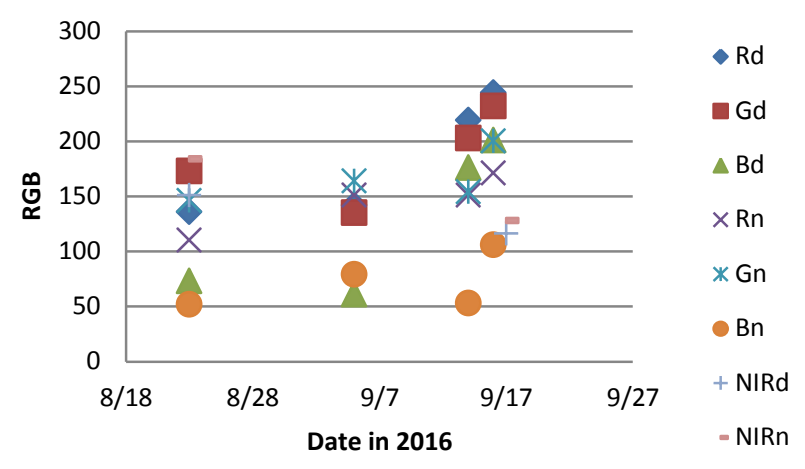

Fig. 5. RGB color intensity trend

TABLE I. DETAILED COLOR INTENSITY TREND

\begin{tabular}{|l|l|l|l|l|l|l|}
\hline VIS & $\mathrm{Rd}$ & $\mathrm{Gd}$ & $\mathrm{Bd}$ & $\mathrm{Rn}$ & $\mathrm{Gn}$ & $\mathrm{Bn}$ \\
\hline $8 / 23$ & 136 & 173 & 73 & 110 & 146 & 52 \\
\hline $9 / 5$ & 142 & 135 & 61 & 151 & 164 & 79 \\
\hline $9 / 14$ & 219 & 203 & 176 & 151 & 154 & 53 \\
\hline $9 / 16$ & 244 & 232 & 201 & 171 & 200 & 106 \\
\hline $\mathrm{NIR}$ & $\mathrm{Rd}$ & $\mathrm{Gd}$ & $\mathrm{Bd}$ & $\mathrm{Rn}$ & $\mathrm{Gn}$ & $\mathrm{Bn}$ \\
\hline $8 / 23$ & 235 & 108 & 151 & 249 & 115 & 184 \\
\hline $9 / 17$ & 243 & 103 & 116 & 199 & 77 & 128 \\
\hline
\end{tabular}

On the other hand, color intensity of the normal rice paddy field is stable, relatively. Also, it is found that green color intensity has almost same tendency as NIR intensity tendency. Therefore, there is a possibility of estimation of NIR reflectance with green color intensity.

Fig. 6 and Table 2 shows the results from the regressive analysis between RGB and NIR reflectance measured on August 23 and September 17 2016. The determination coefficient is more than 0.94 for the correlation between Green reflectance and NIR reflectance as shown in Fig.6. Therefore, it can be concluded that it is possible to estimate NIR reflectance with green color reflectance. In other word, it is possible to estimate NDVI by using drone mounted visible camera data.

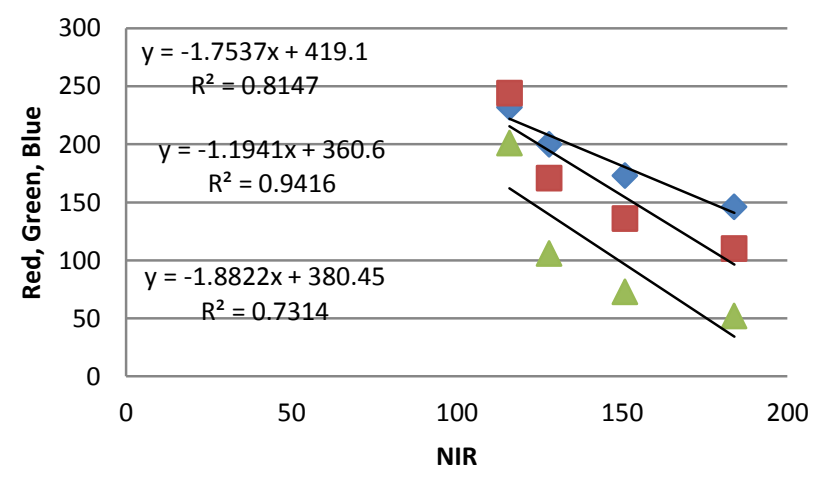

Fig. 6. Results from the regressive analysis 
TABLE II. RELATION BETWEEN NIR INTENSITY AND RGB INTENSITIES

\begin{tabular}{|l|l|l|l|}
\hline NIR & $R$ & G & B \\
\hline 116 & 244 & 232 & 201 \\
\hline 128 & 171 & 200 & 106 \\
\hline 151 & 136 & 173 & 73 \\
\hline 184 & 110 & 146 & 52 \\
\hline
\end{tabular}

\section{CONCLUSION}

Method for Near Infrared: NIR reflectance estimation with visible camera data based on regression for Normalized Vegetation Index: NDVI estimation is proposed together with its application for insect damage detection of rice paddy fields. Through experiments at rice paddy fields which is situated at Saga Prefectural Agriculture Research Institute SPARI in Saga city, Kyushu, Japan, it is found that there is high correlation between NIR reflectance and Green color reflectance. Therefore, it is possible to estimate NIR reflectance with visible camera data which results in possibility of estimation of NDVI with drone mounted visible camera data. As is well known that the protein content in rice crops is highly correlated with NIR intensity, or reflectance of rice leaves, it is possible to estimate rice crop quality with drone based visible camera data.

It can be concluded that it is possible to estimate NIR reflectance with green color reflectance. In other word, it is possible to estimate NDVI by using drone mounted visible camera data.

\section{ACKNOWLEDGEMENT}

Authors would like to thank Mr. Higuchi of student of Saga University for his contribution to conduct field campaign at SPARI.

\section{REFERENCES}

[1] Wiegand, C., Shibayama, M, Yamagata, Y, Akiyama, T., 1989. Spectral Observations for Estimating the Growth and Yield of Rice, Journal of Crop Science, 58, 4, 673-683, 1989.

[2] Kohei Arai, Method for estimation of grow index of tealeaves based on Bi-Directional reflectance function:BRDF measurements with ground based netwrok cameras, International Journal of Applied Science, 2, 2, 52-62, 2011.

[3] Kohei Arai, Wireless sensor network for tea estate monitoring in complementally usage with Earth observation satellite imagery data based on Geographic Information System(GIS), International Journal of Ubiquitous Computing, 1, 2, 12-21, 2011.

[4] Kohei Arai, Method for estimation of total nitrogen and fiber contents in tealeaves with grond based network cameras, International Journal of
Applied Science, 2, 2, 21-30, 2011.

[5] Kohei Arai, Method for estimation of damage grade and damaged paddy field areas sue to salt containing sea breeze with typhoon using remote sensing imagery data, International Journal of Applied Science,2,3,8492, 2011.

[6] Kohei Arai, Monte Carlo ray tracing simulation for bi-directional reflectance distribution function and grow index of tealeaves estimation, International Journal of Research and Reviews on Computer Science, 2, 6, 1313-1318, 2011.

[7] Kohei.Arai, Fractal model based tea tree and tealeaves model for estimation of well opened tealeaf ratio which is useful to determine tealeaf harvesting timing, International Journal of Research and Review on Computer Science, 3, 3, 1628-1632, 2012.

[8] Kohei.Arai, H.Miyazaki, M.Akaishi, Determination of harvesting timing of tealeaves with visible and near infrared cameradata and its application to tea tree vitality assessment, Journal of Japanese Society of Photogrammetry and Remote Sensing, 51, 1, 38-45, 2012

[9] Kohei Arai, Osamu Shigetomi, Yuko Miura, Hideaki Munemoto, Rice crop field monitoring system with radio controlled drone based near infrared cameras through nitrogen content estimation and its distribution monitoring, International Journal of Advanced Research in Artificial Intelligence, 2, 3, 26-37, 2013.

[10] Kohei Arai, Masanori Sakashita, Osamu Shigetomi, Yuko Miura, Estimation of Protein Content in Rice Crop and Nitrogen Content in Rice Leaves Through Regression Analysis with NDVI Derived from Camera Mounted Radio-Control Drone, International Journal of Advanced Research in Artificial Intelligence, 3, 3, 13-19, 2013

[11] Kohei Arai, Masanori Sakashita, Osamu Shigetomi, Yuko Miura, Estimation of Protein Content in Rice Crop and Nitrogen Content in Rice Leaves Through Regression Analysis with NDVI Derived from Camera Mounted Radio-Control Drone, International Journal of Advanced Research in Artificial Intelligence, 3, 3, 13-19, 2013

\section{AUTHORS PROFILE}

Kohei Arai, He received BS, MS and PhD degrees in 1972, 1974 and 1982, respectively. He was with The Institute for Industrial Science and Technology of the University of Tokyo from April 1974 to December 1978 and also was with National Space Development Agency of Japan from January, 1979 to March, 1990. During from 1985 to 1987, he was with Canada Centre for Remote Sensing as a Post-Doctoral Fellow of National Science and Engineering Research Council of Canada. He moved to Saga University as a Professor in Department of Information Science on April 1990. He was a counselor for the Aeronautics and Space related to the Technology Committee of the Ministry of Science and Technology during from 1998 to 2000. He was a councilor of Saga University for 2002 and 2003. He also was an executive councilor for the Remote Sensing Society of Japan for 2003 to 2005. He is an Adjunct Professor of University of Arizona, USA since 1998. $\mathrm{He}$ also is Vice Chairman of the Commission-A of ICSU/COSPAR since 2008. He received Science and Engineering Award of the year 2014 from the minister of the ministry of Science Education of Japan and also received the Bset Paper Award of the year 2012 of IJACSA from Science and Information Organization: SAI. In 2016, he also received Vikram Sarabhai Medal of ICSU/COSPAR and also received 20 awards. He wrote 34 books and published 520 journal papers. He is Editor-in-Chief of International Journal of Advanced Computer Science and Applications as well as International Journal of Intelligent Systsems and Applications. http://teagis.ip.is.sagau.ac.jp/ 